\title{
ANALISIS PENGARUH VARIABEL MAKROEKONOMI TERHADAP RETURN SAHAM SYARIAH SEKTOR PERTANIAN YANG TERDAFTAR DI ISSI PERIODE 2011-20181
}

\author{
Achmad Kharis \\ Departemen Ekonomi Syariah-Fakultas Ekonomi dan Bisnis-Universitas Airlangga \\ Email: achmad.kharis-2014@feb.unair.ac.id \\ Imron Mawardi \\ Departemen Ekonomi Syariah-Fakultas Ekonomi dan Bisnis- Universitas Airlangga \\ Email: ronmawardi@yahoo.co.id
}

\begin{abstract}
:
This study aims to determine the effect of GDP, Inflation, SBIS, Exchange Rates against Returns on Sharia Stocks in the Agriculture Sector Listed in the Indonesian Sharia Stock Index (ISSI). The approach used is quantitative by using the Vector Error Correction Model (VECM) analysis technique with the STATA program. While the GDP, Inflation, SBIS, Exchange Rates as independent variables and Returns on Sharia Stocks in the Agriculture Sector Listed in the Indonesian Sharia Stock Index (ISSI) as the dependent variable. The results of this study indicate that in the short term only GDP has a negative and significant effect. Whereas in the long run the GDP has a negative and significant effect, inflation has a positive and significant effect, SBIS has a negative and significant effect, Exchange rates have a positive and significant effect on the return of Agricultural Sector Sharia Shares registered at ISSI on the research period from 2011 to 2018.
\end{abstract}

Keywords: GDP, Inflation, SBIS, Exchange Rates and Returns on Sharia Stocks in the Agriculture Sector Listed in ISSI.

\section{PENDAHULUAN}

Perkembangan zaman di era globalisasi saat ini telah mempengaruhi perekonomian dunia di mana jarak, waktu, informasi serta tempat bukan menjadi halangan sehingga peluang untuk berinvestasi menjadi semakin efisien dan efektif. Investasi adalah komitmen atas sejumlah dana atau sumber daya lainnya yang dilakukan pada saat ini, dengan tujuan untuk memperoleh sejumlah pengembalian (return) di masa mendatang (Tandelilin, 2010:2). Dengan demikian, kegiatan investasi adalah suatu kegiatan yang dilakukan dengan cara menanamkan sejumlah dana pada suatu aktivitas ekonomi yang produktif dengan harapan dapat menuai hasil dimasa yang akan datang.

Dalam perspektif islam, investasi merupakan bagian dari kegiatan muamalah yaitu suatu kegiatan yang ditentukan Allah SWT untuk mengatur antara hubungan manusia dengan manusia dalam mencapai kemaslahatan. Dalam hal ini, investasi merupakan kegiatan muamalah dalam bidang ekonomi. Jika mengacu pada salah satu kaidah dalam figh muamalah, "Hukum asal dari sesuatu (muamalah) adalah mubah sampai ada dalil yang melarangnya (memakruhkan atau mengharamkannya)". Maka, segala bentuk kegiatan investasi diperbolehkan

\footnotetext{
${ }^{1}$ Jurnal ini adalah bagian dari skrispi Achmad Kharis, NIM: 041411431037, yang diuji pada tanggal 17 Juli 2019.
} 
Kharis, et al/Jurnal Ekonomi Syariah Teori dan Terapan Vol. 6 No. 10 Oktober 2019: 1953-1965; ANALISIS PENGARUH VARIABEL MAKROEKONOMI TERHADAP RETURN SAHAM SYARIAH SEKTOR PERTANIAN YANG TERDAFTAR DI ISSI PERIODE 2011-2018

sampai ada dalil yang melarangnya.

Terdapat berbagai macam sarana dalam kegiatan investasi. Pasar modal memiliki peran penting bagi perekonomian suatu negara sebagai sarana yang bertugas menjadi perantara antara pihak yang memiliki kelebihan dana (pemodal) dengan pihak yang membutuhkan dana untuk dikelola. Pasar modal syariah merupakan kegiatan pasar modal yang memiliki karakteristik khusus yaitu bahwa produk dan mekanisme transaksi tidak boleh bertentangan dengan prinsip syariah yang sudah ditetapkan oleh Dewan Syariah Nasional Majelis Ulama Indonesia.

Salah satu instrumen yang populer di pasar modal adalah saham. Menerbitkatkan saham merupakan salah satu cara bagi perusahaan untuk mendapatkan pendanaan. Saham yang tidak bertentangan dengan prinsip syariah di pasar modal adalah saham syariah. Terdapat berbagai macam indeks pada saham syariah yaitu salah satunya adalah Indeks Saham Syariah Indonesia. Indeks Saham Syariah Indonesia (ISSI) diterbitkan pada tanggal 12 Mei 2011 adalah indeks komposit saham syariah yang tercatat di BEI. ISSI merupakan indikator dari kinerja pasar saham syariah Indonesia (www.idx.co.id).

Terdapat berbagai macam sektor saham syariah yang terdapat di Indeks Saham Syariah Indonesia (ISSI), salah satunya adalah sektor pertanian. Indonesia memiliki potensi sumber daya alam yang melimpah sehingga dapat menunjang produksi pertanian. Pertumbuhan penduduk di Indonesia terus meningkat. Maka, sektor pertanian harus terus tumbuh untuk meningkatkan produksi agar dapat memenuhi kebutuhan dalam negeri. Potensi peningkatan produksi akan membuat investor optimis untuk berinvestasi pada sektor pertanian. Optimisnya investor dapat dilihat dari perkembangan data realisasi investasi. Menurut Suwendi (2017) dalam bukunya yang berjudul Statistik Makro Sektor Pertanian menjelaskan bahwa data realisasi investasi merupakan data kegiatan investasi yang direalisasikan oleh perusahaan dalam bentuk kegiatan nyata yang sudah menghasilkan produk barang atau jasa dan perusahaan yang memperoleh izin usaha tetap dari pemerintahan.

Berdasarkan data realisasi investasi yang terdapat pada Badan Koordinasi Penanaman Modal Republik Indonesia, tahun 2013 sampai tahun 2017 tingkat penanaman modal dalam negeri pada sektor pertanian terus meningkat dari tahun 2013 sebesar 6,9 triliun rupiah hingga pada tahun 2017 menjadi sebesar 22,8 triliun rupiah. Tercatat nilai penanaman modal dalam negeri tertinggi pada tahun 2017 di sektor pertanian sebesar 22,8 triliun rupiah. Data tersebut mengindikasikan bahwa minat investor dalam negeri terhadap sektor pertanian dari tahun 2013 sampai tahun 2017 meningkat. Namun tingkat penanaman 
Kharis, et al/Jurnal Ekonomi Syariah Teori dan Terapan Vol. 6 No. 10 Oktober 2019: 1953-1965; ANALISIS PENGARUH VARIABEL MAKROEKONOMI TERHADAP RETURN SAHAM SYARIAH SEKTOR PERTANIAN YANG TERDAFTAR DI ISSI PERIODE 2011-2018

modal asing pada sektor pertanian bergerak fluktuatif. Tingkat penanaman modal asing tertinggi ada pada sektor pertambangan pada tahun 2013 dengan nilai sebesar 4,8 triliun rupiah. Serta dari tahun 2013 sampai tahun 2017 tingkat penanaman modal asing terbesar terletak pada sektor pertambangan. Hal tersebut mengindikasikan bahwa minat investor asing terletak pada sektor pertambangan.

Tujuan investor berinvestasi adalah memaksimalkan return agar dapat menikmati sebagian dana yang sudah diinvestasikan. Penentuan investasi di pasar modal perlu mengkaji kinerja operasi perusahaan agar mendapatkan return sesuai yang diharapkan. Kinerja operasi perusahaan dapat dipengaruhi oleh faktor-faktor makro ekonomi. Faktorfaktor ekonomi makro secara empiris telah terbukti mempunyai pengaruh terhadap perkembangan investasi di berbagai negara (Tandelilin,2010:343). variabel makro yang digunakan antara lain: pertumbuhan Produk Domestik Bruto (PDB), inflasi, Setifikat Bank Indonesia Syariah (SBIS) dan nilai tukar mata uang (kurs).

Pertumbuhan PDB merupakan sinyal positif untuk investasi. Jika pertumbuhan ekonomi membaik, maka daya beli masyarakat pun akan membaik, dan terdapat peluang bagi perusahaan untuk meningkatkan penjualannya. Dengan meningkatnya penjualan maka keuntungan yang diperoleh juga semakin meningkat (Tandelilin, 2010: 342).
Peningkatan inflasi secara relatif merupakan sinyal negatif bagi pemodal di pasar modal. Inflasi yang tinggi juga dapat mengurangi tingkat pendapatan riil yang di peroleh investor dari investasinya (Tandelilin, 2010: 343). Tingkat imbalan Sertifikat Bank Indonesia Syariah (SBIS) akan mempengaruhi bank syariah untuk berinvestasi di SBIS, dengan begitu bank syariah akan mendapatkan keuntungan, dan bagi hasil pada nasabah tabungan atau deposito juga akan meningkat. Hal tersebut dapat mempengaruhi investor untuk beralih berinvestasi dibank syariah dibandingkan pasar modal.

Terdapatnya perusahaan yang menggunakan ekspor impor dari dan ke luar negeri untuk menjalankan proses bisnisnya sehingga hal inilah yang menyebabkan nilai tukar rupiah menjadi salah satu faktor penting bagi keberlangsungan bisnisnya dan dapat mempengaruhi return saham jika terjadi perubahan kurs rupiah (Mayfi dan Rudianto, 2014).

\section{LANDASAN TEORI}

Menurut Tandelilin (2010:28), pasar modal terbagi menjadi 2 jenis yaitu pasar perdana dan pasar sekunder. Pasar perdana adalah suatu kondisi dimana saham pertama kali diterbitkan dan dijual pada investor. Sebelum menawarkan saham dipasar perdana, perusahaan emiten akan mengeluarkan informasi mengenai perusahaan secara detail agar investor bisa mengetahui prospek perusahaan tersebut. Hasil penjualan 
Kharis, et al/Jurnal Ekonomi Syariah Teori dan Terapan Vol. 6 No. 10 Oktober 2019: 1953-1965; ANALISIS PENGARUH VARIABEL MAKROEKONOMI TERHADAP RETURN SAHAM SYARIAH SEKTOR PERTANIAN YANG TERDAFTAR DI ISSI PERIODE 2011-2018

saham seluruhnya masuk pada modal perusahaan. Pasar sekunder adalah tempat jual beli sekuritas antar investor setelah sekuritas emiten di jual dipasar perdana. Maka hasil dari perdagangan tidak masuk kedalam modal perusahaan.

Pengertian pasar modal syariah di dalam Fatwa DSN MUI No.40/DSNMUI/X/2003 adalah pasar modal yang seluruh mekanisme kegiatannya mulai dari emiten, jenis sekuritas yang diperdagangkan, dan mekanisme perdagangannya telah memenuhi prinsipprinsip syariah. Prinsip-prinsip syariah yang dimaksud adalah prinsip- prinsip yang didasarkan atas ajaran Islam yang penetapannya dilakukan oleh DSN MUI melalui fatwa.

Fatwa DSN-MUI No: 40/DSN$\mathrm{MUI} / \mathrm{X} / 2002$ Pasal 3, tentang Pasar Modal dan Pedoman Umum Penerapan Prinsip Syariah di Bidang Pasar Modal memiliki empat kriteria penilaian atas kelayakan emiten yang mengeluarkan/menerbitkan efek syariah sebagai berikut:

1. Jenis usaha, produk barang dan jasa yang diberikan, serta tata cara pengelolaan perusahaan tidak boleh bertentangan dengan prinsip-prinsip syariah.

2. Jenis kegiatan usaha yang bertentangan dengan prinsip-prinsip syariah antara lain:

a. Segala kegiatan yang mengandung unsur judi.

b. Lembaga maupun badan usaha yang mengandung unsur riba, termasuk bank konvensional, asuransi konvensional, pegadaian, dll.

c. Produsen, distributor, serta pedagang yang menjual produk yang haram.

d. Produsen, distributor, serta pedagang yang menjual produk yang dapat merusak moral dan bersifat mudarat.

3. Emiten yang bermaksud menerbitkan Efek Syariah wajib untuk menandatangani dan memenuhi ketentuan akad yang sesuai dengan fatwa DSN-MUI.

4. Emiten yang menerbitkan Efek Syariah wajib menjamin bahwa kegiatan usahanya memenuhi prinsip-prinsip syariah dan memiliki Shariah Compliance Officer.

Peraturan Bapepam-LK No: KEP130/BL/2006 ditindaklanjuti dengan peraturan No: KEP-314/BL/2007 tentang kriteria dan penerbitan Daftar Efek Syariah yang dimuat dalam Peraturan II.K.1, yaitu tidak boleh melebihi rasio-rasio keuangan sebagai berikut:

1.(Hutang yang berbasis bunga dibandingkan dengan total ekuitas tidak lebih dari 45\%:55\%)

2.Total pendapatan bunga dan pendapatan tidak halal lainnya dibandingkan total pendapatan (revenue) tidak lebih dari 10\%.

Return saham adalah tingkat keuntungan yang dinikmati oleh pemodal atas suatu investasi saham yang dilakukan 
Kharis, et al/Jurnal Ekonomi Syariah Teori dan Terapan Vol. 6 No. 10 Oktober 2019: 1953-1965; ANALISIS PENGARUH VARIABEL MAKROEKONOMI TERHADAP RETURN SAHAM SYARIAH SEKTOR PERTANIAN YANG TERDAFTAR DI ISSI PERIODE 2011-2018

(Mayfi dan Rudianto, 2014). Produk domestik bruto (PDB) adalah salah satu ukuran yang mencerminkan kinerja ekonomi suatu negara. PDB menyatakan pendapatan total dan pengeluaran total nasional pada output barang dan jasa (Mankiw,2000:15). Menurut Sukirno (2004:27) memberikan definisi bahwa inflasi adalah suatu proses kenaikan harga-harga yang berlaku dalam suatu perekonomian.

Menurut Fatwa Dewan Syariah Nasional No: 63/DSN-MUI/XII/2007 bahwa Sertifikat Bank Indonesia Syariah (SBIS) adalah surat berharga dalam mata vang Rupiah yang diterbitkan oleh Bank Indonesia berjangka waktu pendek berdasarkan prinsip syariah. Kurs atau nilai tukar adalah suatu nilai yang menunjukkan jumlah nilai mata vang dalam negeri yang diperlukan untuk mendapatkan satu unit mata vang asing (Sukirno, 2006:237).

Berdasarkan hasil penelitian yang dilakukan oleh Hussin et al (2012) menunjukkan bahwa GDP memiliki pengaruh positif dan signifikan terhadap returns saham. Dengan asumsi peningkatan GDP riil akan memiliki pengaruh pada harga saham melalui laba perusahaan. Hal tersebut terjadi karena ketika terjadi peningkatan GDP riil, arus kas masa depan yang diharapkan di perusahaan akan meningkat yang tercermin dalam meningkatnya harga saham perusahaan. Menurut Triayuningsih (2003) Kondisi inflasi yang tinggi membuat harga barang-barang atau bahan baku cenderung meningkat. Peningkatan bahan baku akan membuat produksi menjadi tinggi, sehingga akan berpengaruh pada penurunan permintaan. Akibatnya jumlah penjualan akan menurun serta di ikuti penurunan pendapatan perusahaan. Maka akan berdampak buruk terhadap kinerja perusahaan yang tercermin dengan turunnya harga saham perusahaan.

Ketika imbalan yang diperoleh bank syariah dalam melakukan investasi SBIS itu besar tentu keuntungan akan diperoleh bank Syariah juga besar, selanjutnya return yang dibagi hasilkan pada DPK (Dana Pihak Ketiga) yaitu para nasabah yang menabung, deposito juga akan tinggi. Hal tersebut mampu menarik investor untuk beralih berinvestasi dibank syariah daripada instrumens investasi lainnya seperti pasar modal syariah. Ketika minat investor turun untuk berinvestasi dipasar modal syariah tentu hal itu akan memicu menurunya indeks saham syariah (Suciningtyas dan Khoiroh, 2015). Sehingga dapat disimpulkan bahwa Sertifikat Bank Indonesia Syariah memiliki pengaruh negatif dan signifikan terhadap return saham.

Berdasarkan penelitian yang dilakukan oleh Hussin et al (2012), mengasumsikan bahwa jika suatu negara bergantung pada ekspor, penurunan nilai mata vang (depresiasi) akan meningkatkan pertumbuhan ekspor. Namun, penurunan nilai mata uang akan 
Kharis, et al/Jurnal Ekonomi Syariah Teori dan Terapan Vol. 6 No. 10 Oktober 2019: 1953-1965; ANALISIS PENGARUH VARIABEL MAKROEKONOMI TERHADAP RETURN SAHAM SYARIAH SEKTOR PERTANIAN YANG TERDAFTAR DI ISSI PERIODE 2011-2018

berdampak pada meningkatnya biaya produksi serta meningkatkan harga domestik sehingga akan menurunkan keuntungan perusahaan. Maka dapat disimpulkan bahwa nilai tukar (kurs) memiliki pengaruh negatif dan signifikan terhadap return saham.

Dalam penelitian ini akan dirumuskan hipotesis sebagai berikut:

1. GDP memiliki pengaruh positif dan signifikan dalam jangka pendek dan jangka panjang terhadap Return Saham Sektor Pertanian yang terdaftar di Indeks Saham Syariah Indonesia (ISSI).

2. Inflasi memiliki pengaruh negatif dan signifikan dalam jangka pendek dan jangka panjang terhadap Return Saham Sektor Pertanian yang terdaftar di Indeks Saham Syariah Indonesia (ISSI).

3. Sertifikat Bank Indonesia Syariah (SBIS) memiliki pengaruh negatif dan signifikan dalam jangka pendek dan jangka panjang terhadap Return Saham Sektor Pertanian yang terdaftar di Indeks Saham Syariah Indonesia (ISSI).

4. Nilai Tukar Rupiah memiliki pengaruh negatif dan signifikan dalam jangka pendek dan jangka panjang terhadap Return Saham Sektor Pertanian yang terdaftar di Indeks Saham Syariah Indonesia (ISSI).

\section{METODE PENELITIAN}

Pendekatan kuantitatif pada penelitian ini menggunakan metode
VECM (Vector Error Correction Model) dengan alat uji statistik menggunakan aplikasi STATA.14. terdapat empat variabel eksogen dan satu variabel endogen dalam penelitian ini, sebagai berikut:

1. Variabel Eksogen adalah GDP $(X 1)$, Inflasi (X2), SBIS (X3), Nilai Tukar Rupiah (X4).

2. Variabel Endogen adalah Return Saham.

Dengan periode kuartalan dari kuartal ke 3 bulan Desember 2011 hingga kuartal ke 4 bulan Desember 2018.

VECM digunakan untuk mengestimasi data yang tidak stasioner pada tingkat level, namun memiliki hubungan kointegrasi (Wisnu, dkk, 2016). Tahap analisis yang digunakan adalah sebagai berikut:

\section{Uji Stasioner}

Tahap pertama yang dilakukan untuk pengolahan data time series adalah dengan menguji stasionaritas data atau biasa disebut dengan uji akar unit (unit root test). Uji akar unit dilakukan untuk mengetahui apakah data yang diamati stasioner atau tidak. Data yang stasioner akan mempunyai kecenderungan untuk mendekati nilai rata-rata dan berfluktuasi disekitar rata-ratanya (Gujarati, 2012).

\section{Uji Lag Optimal}

Menurut Ariefianto (2012) dalam safiroh, dkk (2018), penentuan lag optimal adalah langkah yang sangat penting dalam model VAR/VECM. Lag yang terlalu sedikit atau pendek akan berpotensi menimbulkan masalah bias spesifikasi 
Kharis, et al/Jurnal Ekonomi Syariah Teori dan Terapan Vol. 6 No. 10 Oktober 2019: 1953-1965; ANALISIS PENGARUH VARIABEL MAKROEKONOMI TERHADAP RETURN SAHAM SYARIAH SEKTOR PERTANIAN YANG TERDAFTAR DI ISSI PERIODE 2011-2018

sedangkan jika terlalu banyak atau panjang akan menurunkan degree of freedom sehingga estimasi menjadi tidak efisien.

\section{Uji Kointegrasi}

Menurut Gujarati (2012) dalam Kristanti FT dan Lathifah NT (2013), kedua variabel bisa kointegrasi apabila mereka memiliki hubungan jangka panjang, atau keseimbangan antara keduanya. Granger mengatakan bahwa uji kointegrasi dapat dipandang sebagai tes pendahuluan (pre-test) untuk menghindari adanya regresi spurious.

\section{Uji Model VECM}

Model VECM digunakan di dalam model VAR non struktural untuk data time series yang tidak stasioner pada tingkat level, tetapi stasioner pada tingkat diferensi dan memiliki hubungan kointegrasi. VECM merestriksi hubungan perilaku jangka panjang antar variabel agar konvergen ke dalam hubungan kointegrasinya, namun tetap membiarkan perubahan-perubahan dinamis jangka pendek.

\section{HASIL PENELITIAN}

Uji Stasioneritas Data

Tabel 1.

Hasil Uji Stasioner Data Tingkat Level

\begin{tabular}{|c|c|c|c|c|}
\hline Var. & ADF & $\begin{array}{c}\text { Value } \\
5 \%\end{array}$ & Prob. & Ket. \\
\hline $\begin{array}{c}\text { Retu } \\
\text { rn }\end{array}$ & $-6,28$ & $-2,98$ & 0,000 & Stasioner \\
\hline GDP & $-5,47$ & $-2,98$ & 0,000 & Stasioner \\
\hline $\begin{array}{c}\text { Inflas } \\
\mathrm{i}\end{array}$ & $-6,59$ & $-2,98$ & 0,000 & Stasioner \\
\hline SBIS & $-1,37$ & $-2,98$ & 0,593 & $\begin{array}{c}\text { Tidak } \\
\text { Stasioner }\end{array}$ \\
\hline
\end{tabular}

\begin{tabular}{|l|l|l|l|c|}
\hline Kurs & $-1,38$ & $-2,98$ & 0,588 & $\begin{array}{c}\text { Tidak } \\
\text { stasioner }\end{array}$ \\
\hline
\end{tabular}

Sumber:: hasil Uji STATA (diolah)

Berdasarkan hasil uji stasioneritas data diatas dapat diketahui bahwa masih terdapat variabel yang belum stasioner sehingga penelitian akan dilanjutkan dengan uji stasioneritas data turunan pertama atau first difference.

Uji Stasioner Turunan Pertama Tabel 2.

Hasil Uji Stasioner first difference

\begin{tabular}{|c|c|c|c|c|}
\hline Var & $A D F$ & $\begin{array}{c}\text { Value } \\
5 \%\end{array}$ & Prob & Ket. \\
\hline dReturn & $-9,152$ & $-2,99$ & 0,0000 & Stasioner \\
\hline dGDP & $-5,443$ & $-2,99$ & 0,0000 & Stasioner \\
\hline dlnflasi & $\begin{array}{l}- \\
11,101\end{array}$ & $-2,99$ & 0,0000 & Stasioner \\
\hline dSBIS & $-3,769$ & $-2,99$ & 0,0032 & Stasioner \\
\hline dKurs & $-5,167$ & $-2,99$ & 0,0000 & stasioner \\
\hline
\end{tabular}

Sumber:: hasil uji STATA (diolah)

Setelah dilakukan uji stasioner pada turunan pertama, dapat dilihat pada tabel diatas bahwa semua variabel memiliki nilai probabilitas kurang dari tingkat signifikansi 0,05 atau $5 \%$ yang artinya semua data yang digunakan telah stasioner sehingga dapat dilanjutkan pada tahap selanjutnya.

\section{Pemilihan Lag Optimal}

Pemilihan lag diperlukan untuk mengetahui lama periode respon pada variabel terhadap variabel masa lalu dan terhadap variabel independen. Penetuan lag ditentukan menggunakan pendekatan Likehood Ratio, Final Prediction Error, Akaike Information Criterion, Schwarz Information Criterion dan Hanan Quinn. 
Kharis, et al/Jurnal Ekonomi Syariah Teori dan Terapan Vol. 6 No. 10 Oktober 2019: 1953-1965; ANALISIS PENGARUH VARIABEL MAKROEKONOMI TERHADAP RETURN SAHAM SYARIAH SEKTOR PERTANIAN YANG TERDAFTAR DI ISSI PERIODE 2011-2018

Hasil pemilihan lag pada penelitian ini menggunakan lag 2 karena adanya informasi pada masing-masing metode yang digunakan dan dibuktikan dengan tanda bintang $(*)$ pada hasil penelitian.

\section{Kointegrasi Johansen}

Tabel 3.

Uji Kointegrasi Johansen

\begin{tabular}{|c|c|c|c|}
\hline $\begin{array}{c}\text { Max } \\
\text { Rank }\end{array}$ & Eigenvalue & $\begin{array}{c}\text { Trace } \\
\text { Statistic }\end{array}$ & $\begin{array}{c}\mathbf{5 \%} \\
\text { Critical } \\
\text { Value }\end{array}$ \\
\hline 0 & - & 171,8638 & 68,52 \\
\hline 1 & 0,95581 & 87,6411 & 47,21 \\
\hline 2 & 0,74154 & 51,1100 & 29,68 \\
\hline 3 & 0,63426 & 23,9525 & 15,41 \\
\hline 4 & 0,43263 & 8,6503 & 3,76 \\
\hline 5 & 0,27413 & - & \multicolumn{1}{|l}{} \\
\hline
\end{tabular}

Sumber:: hasil uji STATA (diolah)

Hasil kointegrasi Johansen dapat dijelaskan bahwa seluruh nilai Trace Statistic lebih besar dari nilai kritis $5 \%$. Dengan demikian hasil uji kointegrasi dalam penelitian ini, mengindikasikan bahwa di antara pergerakan return saham, GDP, inflasi, SBIS, dan nilai tukar (kurs) terdapat hubungan keseimbangan dan kesamaan pergerakan dalam jangka panjang.

\section{Estimasi VECM}

Tabel 4.

Hasil Estimasi VECM Jangka Pendek

\begin{tabular}{|l|l|l|l|l|}
\hline & Koef. & $\begin{array}{l}\text { Std. } \\
\text { Error }\end{array}$ & $\begin{array}{l}\mathrm{P}> \\
|\mathrm{z}|\end{array}$ & Ket \\
\hline dgdp & $-2,990$ & 1,122 & 0,008 & $\begin{array}{l}\text { Negatif } \\
\text { signifikan }\end{array}$ \\
\hline $\begin{array}{l}\text { dinflas } \\
\mathrm{i}\end{array}$ & 0,015 & 0,014 & 0,283 & $\begin{array}{l}\text { Tidak } \\
\text { signifikan }\end{array}$ \\
\hline dsbis & 15,964 & 8,719 & 0,067 & $\begin{array}{l}\text { Tidak } \\
\text { signifikan }\end{array}$ \\
\hline dkurs & $-0,000$ & 0,000 & 0,174 & $\begin{array}{l}\text { Tidak } \\
\text { Signifikan }\end{array}$ \\
\hline
\end{tabular}

Sumber: hasil uji STATA (diolah)

Tabel estimasi VECM jangka pendek diatas dapat menjelaskan bahwa hanya variabel GDP yang memiliki pengaruh negatif dan signifikan terhadap return saham syariah sektor pertanian. Dibuktikan dengan nilai probabilitas $<0.05$ atau $5 \%$.

Tabel 5.

Hasil Estimasi VECM Jangka Panjang

\begin{tabular}{|l|c|c|l|l|}
\hline & Koef. & $\begin{array}{l}\text { Std. } \\
\text { Error }\end{array}$ & $\begin{array}{l}\mathrm{P}> \\
|\mathrm{z}|\end{array}$ & Ket \\
\hline dgdp & $-59,25$ & 3,57 & 0,000 & $\begin{array}{l}\text { Negatif } \\
\text { signifikan }\end{array}$ \\
\hline $\begin{array}{l}\text { dinflas } \\
\mathrm{i}\end{array}$ & 0,345 & 0,14 & 0,014 & $\begin{array}{l}\text { Positif } \\
\text { signifikan }\end{array}$ \\
\hline dsbis & -43.41 & 19,84 & 0,029 & $\begin{array}{l}\text { Negatif } \\
\text { signifikan }\end{array}$ \\
\hline dkurs & 0,004 & 0,000 & 0,048 & $\begin{array}{l}\text { Positif } \\
\text { Signifikan }\end{array}$ \\
\hline
\end{tabular}

Sumber: hasil uji STATA (diolah)

Berdasarkan tabel di atas menunjukkan bahwa dalam jangka panjang variabel GDP terhadap return saham memiliki hubungan yang negatif dan signifikan. Inflasi terhadap return saham memiliki hubungan yang positif dan signifikan. SBIS terhadap return saham memiliki hubungan yang negatif dan signifikan. Dan variabel kurs terhadap return saham memiliki hubungan yang positif dan signifikan.

\section{Pembahasan}

\section{Pengaruh GDP Terhadap Return Saham}

Berdasarkan hasil analisis yang dilakukan, diketahui bahwa bahwa dalam jangka pendek dan jangka panjang GDP berpengaruh negatif dan signifikan terhadap return saham sektor pertanian yang terdaftar di Indek Saham Syariah (ISSI). Dengan demikian, penelitian ini mengindisikan bahwa dalam jangka pendek maupun jangka panjang ketika GDP mengalami peningkatan maka return 
Kharis, et al/Jurnal Ekonomi Syariah Teori dan Terapan Vol. 6 No. 10 Oktober 2019: 1953-1965; ANALISIS PENGARUH VARIABEL MAKROEKONOMI TERHADAP RETURN SAHAM SYARIAH SEKTOR PERTANIAN YANG TERDAFTAR DI ISSI PERIODE 2011-2018

saham syariah sektor pertanian mengalami penurunan.

Hasil dalam penelitian ini tidak sesuai dengan teori yang dikemukakan oleh Tandelilin (2010:342) yang menyatakan bahwa pertumbuhan PDB merupakan sinyal positif untuk investasi. Jika pertumbuhan ekonomi membaik, maka daya beli masyarakat pun akan membaik, dan terdapat peluang bagi perusahaan untuk meningkatkan penjualannya. Dengan meningkatnya penjualan maka keuntungan yang diperoleh juga semakin meningkat. Dapat disimpulkan bahwa peningkatan PDB dapat meningkatkan daya beli masyarakat terhadap produk-produk perusahaan sehingga meningkatkan profitabilitas perusahaan yang tercermin dalam peningkatan saham.

Hasil penelitian ini sesuai dengan penelitian yang dilakukan oleh Sholikhah (2016) yang menyatakan bahwa GDP memiliki pengaruh negatif dan signifikan terhadap return saham. Pemilihan investasi di pasar modal tidak hanya pada sektor pertanian.

Berdasarkan data yang diperoleh dalam Badan Pusat Statistika, sektor yang memiliki kontribusi terbesar dalam PDB adalah sektor industri, ketika terjadi pertumbuhan ekonomi di Indonesia, investor akan menanamkan dananya diluar sektor pertanian karena penyumbangan terbesar dalam perekonomian di Indonesia bukan pada sektor pertanian yang mengindikasikan bahwa terdapat sektor lain yamg memiliki kinerja lebih baik daripada sektor pertanian.

Investor akan memilih berinvestasi pada sektor maupun perusahaan yang dinilai lebih banyak memberikan keuntungan sehingga beralihnya investor pada sektor selain pertanian akan menurunkan harga dan return saham syariah sektor pertanian.

\section{Pengaruh Inflasi Terhadap Return Saham}

Hasil analisis yang telah dilakukan menunjukkan bahwa bahwa dalam jangka pendek inflasi berpengaruh tidak signifikan terhadap return saham syariah sektor pertanian namun dalam jangka panjang inflasi berpengaruh positif dan signifikan terhadap return saham sektor pertanian yang terdaftar di Indek Saham Syariah Indonesia (ISSI).

Hasil penelitian ini mendukung dengan penelitian ini sesuai dengan penelitian yang dilakukan oleh Firdausi AN, dkk (2016), yang menyatakan bahwa dalam jangka pendek inflasi berpengaruh tidak signifikan terhadap ISSI dan dalam jangka panjang inflasi berpengaruh positif dan signifikan terhadap ISSI.

Adanya variabel yang tidak signifikan dalam jangka pendek hal ini terjadi karena suatu variabel bereaksi terhadap variabel lainnya membutuhkan waktu (lag), terbukti dengan adanya mekanisme penyesuaian variabel inflasi dari jangka pendek ke jangka panjang. Hasil dalam penelitian ini juga sesuai dengan penelitian yang dilakukan 
Kharis, et al/Jurnal Ekonomi Syariah Teori dan Terapan Vol. 6 No. 10 Oktober 2019: 1953-1965; ANALISIS PENGARUH VARIABEL MAKROEKONOMI TERHADAP RETURN SAHAM SYARIAH SEKTOR PERTANIAN YANG TERDAFTAR DI ISSI PERIODE 2011-2018

oleh Purnawati dan Werastuti (2010) yang menyatakan bahwa dalam jangka panjang inflasi tidak akan memberikan arti yang serius bagi para investor untuk menanamkan dananya di pasar modal. Investor mengerti bahwa dengan adanya inflasi dalam jangka panjang tidak akan membahayakan dananya yang berada di pasar modal. Intervensi yang dilakukan pemerintah dalam menangani laju inflasi memberikan kepercayaan diri yang tinggi bagi para investor untuk tetap menanamkan modalnya di pasar modal.

\section{Pengaruh SBIS Terhadap Return Saham}

Hasil analisis yang telah dilakukan menunjukkan bahwa dalam jangka pendek Sertifikat Bank Indonesia Syariah (SBIS) berpengaruh tidak signifikan terhadap return saham sektor pertanian yang terdaftar di Indek Saham Syariah (ISSI) namun dalam jangka panjang (SBIS) berpengaruh negatif dan signifikan terhadap return saham sektor pertanian yang terdaftar di Indek Saham Syariah (ISSI)

Dalam jangka panjang, hasil dalam penelitian ini sesuai dengan yang dikemukakan dalam penelitian Suciningtyas dan Khoiroh (2015) yang menyatakan bahwa Bank Syariah yang menempatkan dananya pada Sertifikat Bank Indonesia Syariah (SBIS) berhak mendapatkan upah (ujrah) atas jasa membantu pemeliharaan keseimbangan moneter Indonesia. Ketika imbalan yang diperoleh bank syariah dalam melakukan investasi SBIS itu besar tentu keuntungan akan diperoleh bank Syariah juga besar, selanjutnya return yang di bagihasilkan pada DPK (Dana Pihak Ketiga) yaitu para nasabah yang menabung, deposito juga akan tinggi.

Hal tersebut mampu menarik investor untuk beralih berinvestasi dibank syariah daripada instrumens investasi lainnya seperti pasar modal syariah. Ketika minat investor turun untuk berinvestasi dipasar modal syariah tentu hal itu akan memicu menurunya indeks saham syariah.

\section{Pengaruh Nilai Tukar (Kurs) Terhadap} Return Saham

Hasil analisis yang telah dilakukan menunjukkan bahwa dalam jangka pendek kurs berpengaruh tidak signifikan terhadap return saham sektor pertanian namun dalam jangka panjang kurs berpengaruh positif dan signifikan terhadap return saham sektor pertanian yang terdaftar di Indek Saham Syariah (ISSI).

Hasil dalam penelitian ini sesuai dengan penelitian yang dilakukan oleh Dirga SP, dkk (2016) yang menyatakan bahwa dalam jangka panjang kurs berpengaruh positif dan signifikan terhadap return saham subsektor perkebunan. Jika terdapat perusahaan yang menjual hasil produknya dengan segmentasi pasar ekspor yang cukup besar maka saat rupiah terdepresiasi (melemah) akan meningkatkan pendapatan perusahaan yang diikuti juga dengan return sahamnya. 
Kharis, et al/Jurnal Ekonomi Syariah Teori dan Terapan Vol. 6 No. 10 Oktober 2019: 1953-1965; ANALISIS PENGARUH VARIABEL MAKROEKONOMI TERHADAP RETURN SAHAM SYARIAH SEKTOR PERTANIAN YANG TERDAFTAR DI ISSI PERIODE 2011-2018

\section{SIMPULAN}

Berdasarkan analisis yang telah dilakukan, maka kesimpulan yang dapat diperoleh dalam penelitian ini adalah sebagai berikut.

1. GDP berpengaruh negatif dan signifikan dalam jangka pendek maupun jangka panjang terhadap return saham sektor pertanian yang terdaftar di Indek Saham Syariah Indonesia (ISSI).

2. Inflasi berpengaruh tidak signifikan dalam jangka pendek namun berpengaruh positif dan signifikan dalam jangka panjang terhadap return saham sektor pertanian yang terdaftar di Indek Saham Syariah Indonesia (ISSI).

3. Sertifikat Bank Indonesia Syariah (SBIS) berpengaruh tidak signifikan dalam jangka pendek namun berpengaruh negatif dan signifikan dalam jangka panjang terhadap return saham sektor pertanian yang terdaftar di Indek Saham Syariah Indonesia (ISSI).

4. Nilai tukar (kurs) berpengaruh tidak signifikan dalam jangka pendek namun berpengaruh positif dan signifikan dalam jangka panjang terhadap return saham sektor pertanian yang terdaftar di Indek Saham Syariah Indonesia (ISSI).

\section{DAFTAR PUSTAKA}

Abdullah bin Muhammad. 2006. Tafsir Ibnu Katsir. Jilid 1. Bogor: Pustaka Imam As-Syafi'i.

Amal, Ikhlasul. 2017. "Analisis Pengaruh Current Ratio, Net Profit Margin, Bl Rate, GDP dan Inflasi terhadap
Return Saham Perusahaan

Pertambangan di Indeks Saham Syariah Indonesia periode 20122016". Skripsi Fakultas Ekonomi dan Bisnis Universitas Airlangga. Surabaya.

Anshori, Muslich, dan Iswati, Sri. 2009. Buku Ajar Metodologi Penelitian Kuantitatif. Surabaya: Airlangga University Press.

Boediono. 1996. Ekonomi Moneter. Edisi Ketiga. Yogyakarta: Penerbit BPFE Creswell, J. W. 2014. Research design: Qualitative, Quantitative and Mixed Methods Approach, 4 Edition. London: Sage

Darmadji, Tjiptono dan Fakhruddin. (2011). Pasar Modal Indonesia. Edisi ketiga. Jakarta: Salemba Empat.

Dirga, Siregar, dan Sinaga. 2016. Analisis Pengaruh Variabel Makroekonomi terhadap Return Kelompok Saham Subsektor Perkebunan. Jurnal Aplikasi Manajemen Vol 14 No 3.

Dorbusch, R, dan Fishers. 1994. Macroeconomics. USA: Mc Graw Hill Inc.

Fatkhurruzaq AA. 2012. "Dampak Indikator Makroekonomi Terhadap IHSG". Skripsi Fakultas Ekonomi dan Bisnis Universitas Airlangga. Surabaya.

Firdausi, Fahmi, dan Saptono. 2016. Pengaruh Indeks Harga Saham Regional ASEAN dan Variabel Makroekonomi terhadap Indeks 
Kharis, et al/Jurnal Ekonomi Syariah Teori dan Terapan Vol. 6 No. 10 Oktober 2019: 1953-1965; ANALISIS PENGARUH VARIABEL MAKROEKONOMI TERHADAP RETURN SAHAM SYARIAH SEKTOR PERTANIAN YANG TERDAFTAR DI ISSI PERIODE 2011-2018

Saham Syariah Indonesia (ISSI). Jurnal Al-Muzara'ah Vol 4, No 2.

Febrina, Sumiati, dan Ratnawati. 2018. Pengaruh Variabel Makroekonomi dan Harga Saham Asing Terhadap Indeks Harga Gabungan. Jurnal Bisnis dan Manajemen Vol. $5 \mathrm{Nol}$.

Gujarati, D.N., Porter, D.C. 2012. Basics Econometric. R. Dasar-Dasar Ekonometrika. Edisi Kelima. Salemba Empat. Jakarta.

Halim. 2013. Pengaruh makro ekonomi terhadap return saham kapitalisasi besar di bursa efek Indonesia. FINESTA. 1 (2): 108-113.

Huda, Nurul, dan Mustafa Edwin Nasution. 2007. Investasi Pada Pasar Modal Syariah. Jakarta: Kencana.

Huda, Nurul. 2008. Ekonomi Makro Islam. Jakarta:Kencana Prenada Media Group.

Hussin MY, Muhammad F, Abu MF, Awang SA. 2012. Macroeconomic Variables and Malaysian Islamic Stock Market: A time series Analysis. Journal of Business Studies Quarterly. Volume 3. No 4, pp 1-13. Jogiyanto, H. M. (2009). Teori Portofolio dan Analisis Investasi. Edisi Keenam. Yogyakarta: BPFE Universitas Gajah Mada.

Jogiyanto, H.M. (2010). Teori Portofolio dan Analisis Investasi. Edisi Ketujuh. BPFE. Yogyakarta.

Kalsum, Ummi. 2014. Riba dan Bunga Bank dalam Islam. Jurnal Al-Adl Vol.7 No.2. STAIN. Kendari.
Mankiw, N. Gregory. (2006). Pengantar Ekonomi Makro, Edisi Tiga. Penerjemah Chriswan Sungkono. Jakarta: Salemba Empat.

Mayfi F dan Rudianto D. (2014). Jurnal. Analis Pengaruh Faktor Internal dan Eksternal Perusahaan Terhadap Return Saham.

Nugroho, Nugroho dan Rizal. 2016. Analisis Indeks Harga Saham Gabungan dengan Pendekatan Vector Error Correction Model (VECM). Jurnal

Nurlita, Anna. 2014. Investasi di Pasar Modal Syariah Dalam Kajian Islam. Jurnal Penelitian Sosial Keagamaan, Vol. 17, No.1. UIN Sultan Syarif Kasim. Riau

Nopirin. 1997. Ekonomi Moneter. Jakarta: Universitas Terbuka.

Purnawati dan Werastuti. 2013. Faktor Fundamental Ekonomi Makro Terhadap Harga Saham LQ45. Jurnal Keuangan dan Perbankan, Vol 17 no 2.

Rozalinda. 2015. Ekonomi Islam: Teori dan Aplikasinya pada Aktivitas Ekonomi. Jakarta: Rajawali Pers.

Ryandono, Muhammad Nafik Hadi. (2009). Bursa Efek dan Investasi Syariah. Jakarta: PT Serambi IImu Semesta.

Saleh Leni. 2016. Perubahan Nilai Tukar Uang Menurut Perspektif Ekonomi Islam. Jurnal Studi Ekonomi dan Bisnis Islam Vol 1 No 1

Samuelson, Paul A. dan William D. Nordhaus. (1992). Makro Ekonomi, 
Kharis, et al/Jurnal Ekonomi Syariah Teori dan Terapan Vol. 6 No. 10 Oktober 2019: 1953-1965; ANALISIS PENGARUH VARIABEL MAKROEKONOMI TERHADAP RETURN SAHAM SYARIAH SEKTOR PERTANIAN YANG TERDAFTAR DI ISSI PERIODE 2011-2018

Edisi XIV. Alih bahasa: Haris Munandar. Jakarta : Erlangga.

Samuelson, Paul A dan Nordhaus, William D,2004, IImu Makro Ekonomi. Jakarta

PT. Media Edukasi.

Suciningtyas dan Rizki (2015). Jurnal. Analisis Dampak Variabel Makro Ekonomi terhadap Indeks Saham Syariah Indonesia.

Suhendi, Hendi. 2014. Fiqh Muamalah. Jakarta: PT. RajaGrafindo Persada. Ensiklopedi Indonesia (tt.), jilid 1, PT. Ichtiar Baru-van Hove, Jakarta.

Sukirno, Sadono. 2004. Makro Ekonomi Teori Pengantar. Edisi ke-3. Jakarta. PT. Raja Grafindo Persada Sukirno, Sadono. 2006. Ekonomi Pebangunan: Proses, Masalah, dan Dasar Kebijakan. Jakarta: Kencana

Sukirno, Sadono. 2013. Makroekonomi: Teori Pengantar Edisi Ketiga. Depok: Raja Grafindo Persada

Sutedi, A. (2011). Pasar Modal Syariah. Jakarta: Sinar Grafika.

Suwandi. (2017).Statistik Makro Sektor Pertanian. Jakarta. Pusat Data dan Sistem Informasi Pertanian.

Suwandi. (2017).Statistik Makro Sektor Pertanian. Jakarta. Pusat Data dan Sistem Informasi Pertanian.

Soemitra, Andri. 2009. Bank dan Lembaga Kevagan Syariah. Jakarta: Kencana Prenada

Syarifuddin , Amir. (2008), Ushul Fikih. Jilid 1.Bogor: Kencana
Tandelilin, Eduardus. (2010). Portofolio dan Investasi - Teori dan Aplikasi. Yogyakarta: kanisius.

Triayunigsih, Retno. 2003. "Analisis Pengaruh Kinerja Keuangan Perusahaan dan Faktor Ekonomi Makro Terhadap Return Saham Perusahaan Industri Manufaktur Di BEJ Periode 1999-2001. Tesis. Program Magister Manajement Pascasarjana. Universitas Diponegoro. Semarang.

Usman, Yulianty. (2004). -Analisis Pengaruh EVA, MVA, dan Kinerja Keuangan Konvensional terhadap Return Saham di Bursa Efek Jakarta". Tesis Pascasarjana. Universitas Diponegoro. Semarang. Utomo,V.J. 2015. "Efek Hari Libur Lebaran Pada Emiten yang Terdaftar dalam ISSI Periode 2011-2013" Surabaya. Fakultas Ekonomi dan Bisnis Universitas Airlangga.

Zuhra, Amalia. 2015. "Pengaruh Variabel Makro Ekonomi Terhadap Jakarta Islamic Index(JII) Periode 20062014". Skripsi Fakultas Ekonomi dan Bisnis Universitas Airlangga. Surabaya.

www.bi.go.id www.bps.go.id www.ojk.go.id wWw.idx.co.id www.duniainvestasi.com 
Kharis, et al/Jurnal Ekonomi Syariah Teori dan Terapan Vol. 6 No. 10 Oktober 2019: 1953-1965; ANALISIS PENGARUH VARIABEL MAKROEKONOMI TERHADAP RETURN SAHAM SYARIAH SEKTOR PERTANIAN YANG TERDAFTAR DI ISSI PERIODE 2011-2018 